\title{
Inappropriate genetic testing of children
}

In 1994, a working party of the UK Clinical Genetics Society produced a report on the genetic testing of children following a survey of practice and attitudes, largely among professionals in the UK, ${ }^{1}$ and the findings were summarised in an annotation in this journal. ${ }^{2}$ In response to this report, the British Paediatric Association issued a statement to members in March 1996 which referred specifically to testing children for adult onset disease. This statement recommended that it was appropriate to perform predictive testing if the onset of the condition regularly occurs in childhood or if there was a useful medical intervention that can be offered (for example, testing a 9 year old for familial adenomatous polyposis). It declared that it was inappropriate to test for untreatable adult onset diseases (for example, Huntington's disease) when formal genetic testing should wait until the "children" were old enough to request testing for themselves.

A subsequent survey of professionals in 37 countries by Wertz $^{3}$ revealed that the majority of geneticists in northern/western Europe, the USA, and other English speaking countries would refuse testing for adult onset diseases but in Asia, Latin America, and southern/eastern Europe, the majority of geneticists would accede to parental requests.

A new survey of current attitudes and practice in the UK has been commissioned by the Advisory Committee on Genetic Testing and the Department of Health, and some early results have been presented. ${ }^{4}$ A questionnaire was sent to 2040 consultants in paediatrics, genetics, and paediatric surgery and 144 genetic nurses and counsellors. A total of 692 completed responses were received. The response rate by specialty was $32 \%$ for paediatricians, $66 \%$ for geneticists, $28 \%$ for surgeons, and $18 \%$ for nurses/ counsellors. Respondents were asked about tests performed on children under 14 years of age in 1997-98. These tests included the use of imaging and standard haematological and biochemical tests as well as DNA tests and the replies indicated the following:

- In disorders that usually have an adult onset, 165 of the professionals had performed tests on a total of 955 children. The main reason given for performing the test was that the child might get a health benefit as a result. The main reason given for withholding testing was that it removed the child's right to make his or her own decisions when mature enough.

- In childhood onset disorders, 289 professionals performed a total of 5543 tests. The highest testing rates were from haematologists testing for haemoglobinopathies and paediatricians involved with cystic fibrosis patients. The main reason was for health benefit.

- A total of 178 respondents had tested the carrier status of 3319 children for autosomal recessive disorders or chromosomal rearrangements. The main reason given was parental pressure to test. The main reason given for not testing was loss of the child's autonomy.

It is clear therefore that a great deal of testing is being performed and it is appropriate to review the arguments for and against testing.

\section{What approach should be taken to minors requesting tests themselves? At what age can they give consent?}

There have been increasing numbers of requests from young people themselves for testing. Binedell et al propose an assessment approach to requests from adolescents for
Huntington's disease (HD) prediction. ${ }^{5}$ These authors suggest four factors in particular which need consideration: an evaluation of the person's emotional, cognitive, and social maturity; ensuring that the person is acting autonomously; exploration of the role of the family context in the decision; and assessment of the person's experience and confidence in making major personal decisions. In addition, they highlight some particular factors of relevance, including the length of time that the adolescent has lived with the knowledge of HD in the family and his/her at risk status and the way that he/she coped with being informed about the risk.

At what age can a child give consent? In the recent UK survey, it was felt that the maturity of the child was more important than the specific age. Experience of living with the condition can be an important factor in understanding and IQ is not necessarily relevant. In the survey, 10 years was the most cited minimum age quoted by professionals for active involvement in the counselling process; 16 years was the most cited age for giving consent for predictive testing. ${ }^{4}$

\section{Testing in a child who cannot give consent-the dilemma}

From an ethical viewpoint, worries exist about possible long term psychological harm and the fact that testing removes the autonomy over decision making. Furthermore, the confidentiality to which an adult is entitled is breached by disclosing results to the parents, and testing the child breaches the policy of providing counselling to the person being tested before, during, and after the testing process. The concerns about removal of autonomy and confidentiality may be overridden by the responsibility to do what is in the best interests of the child. It is argued that we do not know what the best interests of the child are in the majority of genetic testing situations. ${ }^{6}$ The problem is that very few studies have assessed the short term effects and none have assessed the long term effects of testing for adult onset diseases.

It is clearly appropriate to perform genetic testing of minors when the problem in question can be rectified, treated, or prevented but the decision is difficult when the risk from the test may be significant, the statistical risk of disease is minimal, and the benefit of early diagnosis is small. A variety of arguments have been put forward as potential benefits and these and the potential drawbacks are summarised in table 1 . The use of a diagnostic test for the purpose of information seems highly problematic in the case of childhood testing and it is a controversial question as to whether reduction of parental anxiety by itself justifies testing when there is no clear or immediate medical benefit. ${ }^{8}$ From a legal viewpoint, McLean ${ }^{9}$ argues that burdens should not outweigh benefits. She says that in the absence of convincing arguments to the contrary, it is necessary to err on the side of caution and not be overly willing to permit testing.

In any individual situation, deciding whether the burdens outweigh the benefits can be extremely difficult as exemplified in the debate about testing a newborn child for hypertrophic cardiomyopathy published in the British Medical fournal in $1995,{ }^{10-12}$ and in the cases analysed by Chapple and colleagues. ${ }^{13}$ The most difficult situations arise in relation to adult diseases that can present in childhood (for example, adult polycystic kidney disease), childhood diseases that are not treatable or preventable, and carrier testing for autosomal and $x$ linked recessive diseases or balanced chromosomal rearrangements. 
Table 1 Suggested psychological benefits and dangers from childhood testing (various sources-largely adapted from Michie and Marteau')

\begin{tabular}{|c|c|c|}
\hline Result & Possible danger & Possible benefit \\
\hline Faulty gene absent & $\begin{array}{l}\text { Rejection by family, especially if others affected } \\
\text { False reassurance about health status }\end{array}$ & $\begin{array}{l}\text { Avoid clinical monitoring } \\
\text { Emotional relief } \\
\text { Ability to plan life } \\
\text { Avoids effects of later disclosure } \\
\text { Avoids "preselection" } \dagger \\
\text { Relieves anxiety about possible early signs of the disorder }\end{array}$ \\
\hline Faulty gene present & $\begin{array}{l}\text { Impair child's self esteem } \\
\text { Impair child's long term adjustment } \\
\text { Impair relationship with parents (post-test changes in parental attitudes) } \\
\text { Stigmatisation/overprotection } \\
\text { Discrimination in education, employment, insurance, mortgage } \\
\text { Impair relationships with future partners } \\
\text { Removes autonomy to decline testing } \\
\text { Confirms any "preselection" } \dagger \\
\text { Could generate anxiety about early symptoms } \\
\text { Parental distress/guilt }\end{array}$ & $\begin{array}{l}\text { Child has time to adjust-avoids emotional problems of later } \\
\text { disclosure } \\
\text { Enables parents to prepare child psychologically for the future } \\
\text { Practical preparation for future, e.g. education, career, housing, etc } \\
\text { Child can take informed decisions from early age } \\
\text { Allows openness in families } \\
\text { Child doesn't miss opportunity for testing } \\
\text { Relieves child's anxiety or uncertainty about the future } \\
\text { Relieves parents' anxiety or uncertainty } \\
16 \text { years may not be a good age to be tested } \\
\text { ?Beneficence^ } \\
\text { ?Lessens society^ discrimination }\end{array}$ \\
\hline
\end{tabular}

${ }^{\star}$ Cohen $^{25}$ argues that testing respects the principle of beneficence (it is not necessarily unethical for a parent to make choices for a child's welfare) and may lead to possible lessening of discrimination (as society realises that everyone carries "faulty genes").

†Preselection - the concept that in some families persons are singled out for no rational reason as being the ones destined to develop the disorder. This can have adverse effects on the development of the "preselected" child.

\section{The evidence}

There is evidence from a variety of studies to suggest that being a carrier of a genetic disease can be associated with stigmatisation, discrimination, anxiety about future health, and loss of self esteem. ${ }^{14}$ Could this be potentially damaging if testing is performed as a child or could there be benefits from the information being gently introduced during the course of the child's development? A survey of parents in a cystic fibrosis clinic found that most wanted to know their children's carrier status and the large majority felt that it would not alter their child's upbringing - as the parents themselves are carriers, they should realise that being a carrier is not harmful. ${ }^{15}$

A few small retrospective studies have assessed the effects in those families where testing has been performed in childhood. Barnes performed a questionnaire study of 103 parents whose children had been tested for balanced chromosomal translocations (nearly $80 \%$ of whom had been tested prenatally) and found no obvious evidence of harm. This was based on a survey of the parents rather than assessments of the children. Nearly $78 \%$ of the children had not yet been informed of the result. None of the parents regretted having the children tested ${ }^{16}$ even though some parents had suffered considerable distress when finding out that their child was a carrier. Similarly, a Finnish study ${ }^{17}$ is looking at childhood testing in Xp21 dystrophies, haemophilia $\mathrm{A}$ and $\mathrm{B}$, and translocations by questionnaires to parents and those children now over 15 years of age. Preliminary results indicate no psychological harm but many of the children had not heard the results or had misunderstood them.

Jolly et al assessed 10 families where children were tested for balanced translocations and where those children were now over 10 years of age. ${ }^{18}$ The children described their reactions to hearing the result of the test and these varied from initial shock and anxiety to calm acceptance. The effect depended to some extent on the family's experience. Some children experienced a phase where they had feelings of stigmatisation, consistent with the findings of Wolff et al in adults. ${ }^{19}$ Others experienced no more than a mild stigma, if any at all. Some experienced anxiety but this was transient. None of the children resented having been tested and some were glad that they had been tested when they were younger. The Genetics Interest Group's member societies have carried out small scale studies, including interviews with teenagers who were tested as children. These indicated that some who were tested would have preferred not to have been and some not tested would have preferred to have been. Thus, no general rule could be applied..$^{20}$
Can we draw up any guidelines?

What is inappropriate?

- Nearly all agree that testing should not be performed in adult onset diseases where there is no treatment and where many adults decline testing, such as Huntington's disease. Sharpe has argued that it may be more harmful not to test in some situations (for example, parents misinterpreting behavioural problems as manifestations of HD. Could refusal to test in these circumstances result in a distortion of parentchild or sib-sib relationship?). He argues that parents are in a better position to decide than professionals. ${ }^{21}$ Such views are very much in the minority. It is an interesting exercise to consider what tests one might request oneself if given the option. ${ }^{22}$

- Testing would be very doubtful in those disorders with an adult onset where the genotype may not predict phenotype, even if a potential treatment is available, for example, haemochromatosis. ${ }^{23}$

- Testing is doubtful in those disorders with an adult onset even if there may be avoidable precipitants, for example, acute intermittent porphyria or thrombophilias (such as factor V Leiden, where female carriers might want to avoid the contraceptive pill). This can be encountered when reports from haematology laboratories identify carriers of thrombophilic mutations and suggest that other family members be tested, without any advice about the age at which testing is appropriate. Careful thought needs to be given to the wording of laboratory reports.

- At prenatal diagnosis, inadvertent carrier testing of females for $\mathrm{X}$ linked recessive disorders should be avoided.

- Commercial testing? The UK Advisory Committee on Genetic Testing considered the whole issue of testing supplied direct to the public, including the testing of children. In a report published in 1997, it concluded that these services should not be supplied to those under 16 years of age or those unable to make a competent decision regarding testing. ${ }^{24}$

- Susceptibility testing? Genes which confer susceptibility for complex disorders such as diabetes and coronary artery disease are now being discovered. It would be inappropriate to offer any testing for these genes unless there was a clear intervention that could be offered.

In terms of carrier testing, my view is to support the statements in the original CGS report ${ }^{1}$ where it was felt wiser to defer carrier testing for recessive disorders and 
balanced chromosomal rearrangements until the child is able to understand the issues and request testing in person, even though there is little current evidence to suggest that it is harmful. Most of the time, parents agree with this view but difficulties arise when one child has been tested inadvertently (for example, prenatally) and they feel it is appropriate for other children to then be tested. Further research is clearly required into the long term effects as, in a number of the surveys, the children were still unaware that they had been tested and it is of concern that some had misunderstood the results. In childhood onset disorders, testing need not be performed before the age at which health benefits accrue.

In those situations where it is deemed appropriate to offer presymptomatic testing or to test a child for carrier status, it is important for the paediatrician or geneticist to discuss the possible pros and cons of testing with the family so that a fully informed decision is reached. Follow up support and counselling should be available to the families, especially in the event of a positive test result and a clear arrangement made with the family to offer counselling to the child at appropriate stages in the future. The small studies so far performed indicate that some children have misunderstood their test results. A follow up arrangement should be made for those families where the decision is made not to test.

Department of Clinical Genetics,

ALAN FRYER

Royal Liverpool Children's Hospital, Alder Hey,

Eaton Road, Liverpool L12 2AP, UK

Alan.Fryer@rlch-tr.nwest.nhs.uk

1 The genetic testing of children. Report of a working party of the Clinical Genetics Society (UK). $₹$ Med Genet 1994;31:785-7.

2 Fryer A. Genetic testing of children. Arch Dis Child 1995;73:97-9.

2 Fryer A. Genetic testing of children. Arch Dis Child 1995;73:97-9. Wertz DC. International perspectives. In: Clarke A, ed. The genetic testing of
children. Oxford, Washington DC: Bios Scientific Publishers, 1998:271-87. children. Oxford, Washington DC: Bios Scientific Publishers, 1998:271-87.
4 Procter AM, Clarke A, Harper PS. Survey of genetic testing in childhood. Poster presentation, British Human Genetics Conference, University of York, 27-29 September 1999

5 Binedell J, Soldan JR, Scourfield J, Harper PS. The genetic testing of children. F Med Genet 1996;33:912-18.
6 Kurtz Z. Appropriate paternalism and the best interests of the child. In: Clarke A, ed. The genetic testing of children. Oxford, Washington DC: Bios Clarke A, ed. The genetic testing of chilc
Scientific Publishers, 1998:237-43.

7 Michie S, Marteau TM. Predictive genetic testing in children: the need for psychological research. In: Clarke A, ed. The genetic testing of children. Oxford, Washington DC: Bios Scientific Publishers, 1998:169-81.

8 Patenaude AF. Cancer susceptibility testing: risks, benefits and personal beliefs. In: Clarke A, ed. The genetic testing of children. Oxford, Washington DC: Bios Scientific Publishers, 1998:145-56.

9 McLean SAM. The genetic testing of children: some legal and ethical concerns. In: Clarke A, ed. The genetic testing of children. Oxford, Washington DC: Bios Scientific Publishers, 1998:17-26.

10 Genetic testing for familial hypertrophic cardiomyopathy in newborn infants. BMF 1995;310:856-9.

11 Goodwin JF. Hypertrophic cardiomyopathy can be treated but not cured. BMF 195;311:58.

12 Marteau T, Michie S. A positive screening test for an untreatable condition provided psychological relief from uncertainty. BMF 1995;311:58-9.

13 Chapple A, May C, Campion P. Predictive and carrier testing of children: professional dilemmas for clinical geneticists. In: Clarke A, ed. The genetic testing of children. Oxford, Washington DC: Bios Scientific Publishers, 1998:195-210

14 Evers-Kiebooms E, Denayer L, Welkenhuysen M, Cassiman J-J, van den Berghe $\mathrm{H}$. A stigmatising effect of the carrier status for cystic fibrosis? Clin Genet 1994;46:336-43.

15 Balfour-Lynn I, Madge S, Dinwiddie R. Testing carrier status in siblings of patients with cystic fibrosis. Arch Dis Child 1995;72:167-8.

16 Barnes C. Testing children for balanced chromosomal translocations: parental views and experiences. In: Clarke A, ed. The genetic testing of children. Oxford, Washington DC: Bios Scientific Publishers, 1998:51-60.

17 Jarvinen $\mathrm{O}$, Kaariainen $\mathrm{H}$. A retrospective study of genetic carrier testing in childhood. In: Clarke A, ed. The genetic testing of children. Oxford, Washington DC: Bios Scientific Publishers, 1998:91-6.

18 Jolly A, Parsons E, Clarke A. Identifying carriers of balanced chromosomal translocations: interviews with family members. In: Clarke A, ed. The genetic testing of children. Oxford, Washington DC: Bios Scientific Publishers, 1998:61-90.

19 Wolff G, Back E, Arleth S, Rapp-Korner U. Genetic counselling in families with inherited balanced translocations: experience with 36 families. Clin Genet 1989;35:404-16.

20 Gillott J. Childhood testing for carrier status: the perspective of the Genetic Interest Group. In: Clarke A, ed. The genetic testing of children. Oxford, Washington DC: Bios Scientific Publishers, 1998:97-102.

21 Sharpe NF. Presymptomatic testing for Huntington's disease: is there a duty to test those under the age of eighteen years? Am $\mathcal{f}$ Med Genet 1993;46:250-3.

22 Motulsky AG. If I had a gene test, what would I have and who would I tell? Lancet 1999;354:si35-7.

23 Collins FS. Shattuck lecture: Medical and societal consequences of the human genome project. $N$ Engl f Med 1999;341:237.

24 Advisory Committee on Genetic Testing. Code of practice and guidance on human genetic testing services supplied direct to the public. London: Health Departments of the United Kingdom, 1997.

25 Cohen CB. Moving away from the Huntington's disease paradigm in the predictive genetic testing of children. In: Clarke A, ed. The genetic testing of children. Oxford, Washington DC: Bios Scientific Publishers, 1998:133-43. 